\title{
Effect of Red Mud on the Corrosion of Reinforced Concrete Studied by Electrochemical Impedance Spectroscopy
}

\author{
D. V. Ribeiro, ${ }^{1}$ C. A. D. Rovere, ${ }^{2}$ C. A. C. Souza, ${ }^{1}$ S. E. Kuri, ${ }^{2}$ J. A. Labrincha, ${ }^{3}$ \\ J. C. C. Abrantes, ${ }^{3,4}$ and M. R. Morelli \\ ${ }^{1}$ Department of Materials Science and Technology, Federal University of Bahia, Rua Aristides Novis 02, Federação, \\ 40210-630 Salvador, BA, Brazil \\ ${ }^{2}$ Department of Materials Engineering, Federal University of São Carlos, Rodovia Washington Luis, Km 235, \\ 13565-905 São Carlos, SP, Brazil \\ ${ }^{3}$ Ceramics and Glass Engineering Department, CICECO, University of Aveiro, Campus Universitário de Santiago, \\ 3810-193 Aveiro, Portugal \\ ${ }^{4}$ UIDM, ESTG, Polytechnic Institute of Viana do Castelo, Avenida do Atlântico, 4900-348 Viana do Castelo, Portugal
}

Correspondence should be addressed to D. V. Ribeiro, verasribeiro@hotmail.com

Received 15 June 2011; Accepted 27 July 2011

Academic Editor: B. Luan

Copyright ( 2011 D. V. Ribeiro et al. This is an open access article distributed under the Creative Commons Attribution License, which permits unrestricted use, distribution, and reproduction in any medium, provided the original work is properly cited.

\begin{abstract}
The corrosion of concrete reinforcement is a worldwide problem with serious consequences to humans, including accidental deaths that may occur due to the degradation of this material. Thus, techniques that can measure concrete reinforcement corrosion and provide a reliable prediction of this phenomenon are fundamental for the technological development of these materials. The corrosion of steel bars embedded in concrete containing varying amounts of red mud (up to $30 \%$ of the total binder) was tested by electrochemical impedance spectroscopy (EIS), under partial immersion in a sodium chloride solution. The addition of red mud delayed the onset of corrosion and possibly also reduced the corrosion rate.
\end{abstract}

\section{Introduction}

The global production of bauxite in 2009 was 205 million tons, and the main producing countries were Australia, China, Brazil, Guinea, India, and Jamaica. Occupying the third position in the world ranking in 2009, Brazil produced 26.6 million tons of bauxite. It also has the world's third largest bauxite ore reserves (around 3.5 billion tons), concentrated mainly in the north of the country (state of Pará) [1]. Roughly $0.3-1.0$ tons of red mud are generated for each ton of aluminum produced. About 10.6 million tons of caustic red mud have been discarded annually during recent years in Brazil, and the global generation of red mud exceeds 117 million tons/year [2].

Alkaline matrices such as that ensured by Portland cement in mortars and concrete are commonly used in waste conditioning. They are inexpensive, show an extensively documented history of safe use, and are a readily accessible technology. Alkalinity greatly reduces the solubility of many hazardous inorganic species and inhibits microbiological processes. Moreover, since these matrices require water for hydration, they may readily incorporate wet wastes [1] such as red mud.

The search for an economically and environmentally viable alternative has led to the study of red mud in various applications, for example, as an adsorbent for removing heavy metals from aqueous solutions [3], as a stabilizing material for clay liners [4], red mud-polymer composites panels as a substitute for wood [5], building materials, that is, bricks [6], ceramics and tiles [7], ceramic glazes [8], and iron-rich cement $[9,10]$.

The high alkalinity of red mud, which was initially a factor of environmental concern, now emerges as a major asset in the attempt to use red mud as an inhibitor of reinforced concrete rebar corrosion by retaining its passivity. To evaluate this possibility, rebar corrodibility was examined by the electrochemical impedance spectroscopy (EIS) technique. 


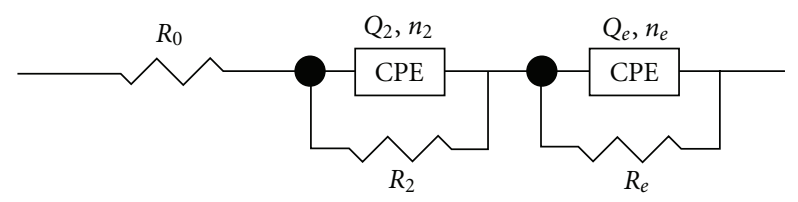

(a)
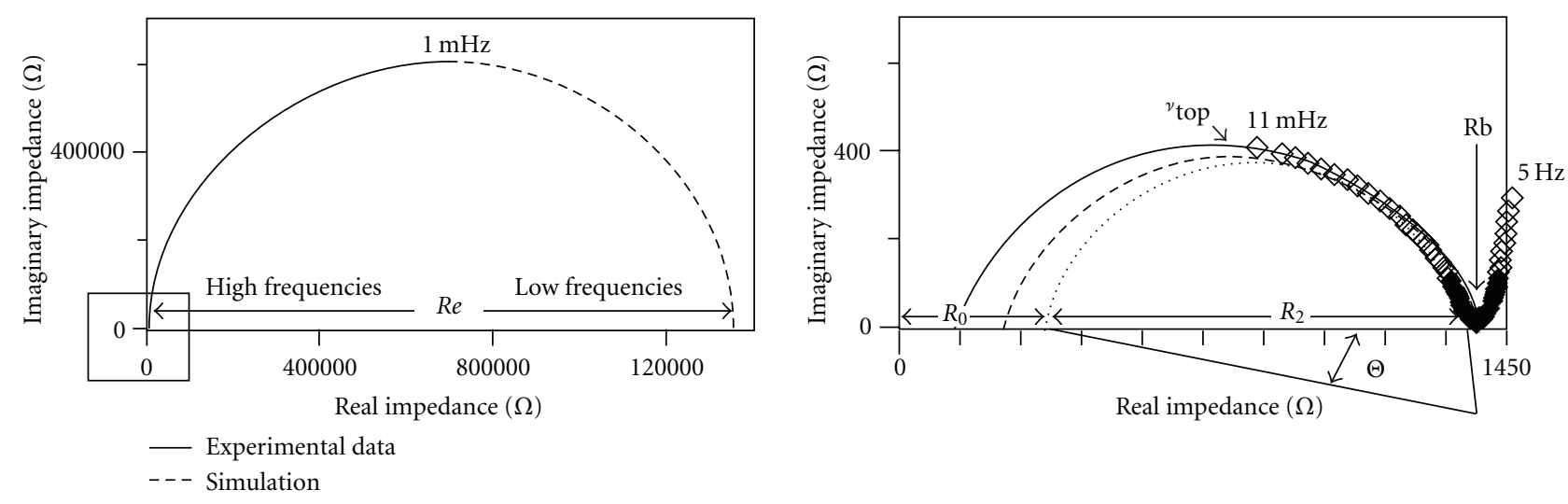

(b)

Figure 1: (a) Typical equivalent circuit, and (b) Nyquist diagram proposed by Christensen et al. [15] for reinforced concrete.

Electrochemical impedance spectroscopy (EIS) is a powerful technique for characterizing a wide variety of electrochemical systems and for determining the contribution of electrode or electrolytic processes in these systems. According to MONTENOR [11], the impedance of an electrical circuit is the measure of its opposition to an electrical signal (potential or current). It is a combination of passive elements of an electrical circuit: resistance, capacitance, and inductance. The EIS technique works in the frequency domain and is based on the concept that an interface can be seen as a combination of passive electrical circuit elements, that is, resistance, capacitance, and inductance. When an alternating current is applied to these elements, the resulting current is obtained using Ohm's law.

For the steel/concrete system, information on several parameters can be obtained, for example, the presence of surface films, characteristics of the concrete, interfacial corrosion, and mass transfer phenomena. However, interpreting the results may be difficult and the use of an equivalent circuit, which can change according to the conditions of the steel, makes the technique more suitable for laboratory studies [11]. The main advantages of EIS are [12]

(i) it provides information about the corrosion kinetics,

(ii) it is an accurate and reproducible technique suitable for highly resistive environments such as concrete,

(iii) it provides data about the electrochemical control mechanism, indicating if corrosion occurs by activation, concentration or diffusion,

(iv) it characterizes the state of the rebar and the morphology of the corrosion,

(v) it is a nondestructive and nonperturbative technique, since the signals applied are of small amplitude, so the corrosion potential is not changed, (vi) it allows for monitoring of the evolution of the passive or active state over time.

The Nyquist diagram consists of a series of points, each of which represents the magnitude and direction of the impedance vector of a particular frequency [13]. The diagram is a complex plane of Cartesian coordinates, where the abscissa is the real part (resistive terms) and the ordinate is the imaginary part (capacitive or inductive terms). Impedance data represented on the Cartesian plane under a wide range of frequencies $(100 \mathrm{KHz}$ to $10 \mathrm{mHz}$, usually $10 \mathrm{KHz}$ to $10^{-4} \mathrm{~Hz}$ ) generate typical configurations according to the predominant electrochemical mechanism.

The diameter of the semicircle extrapolated in the Nyquist diagram represents the charge transfer resistance $R_{t}$ equivalent to the polarization resistance $\left(R_{p}\right)$ [12]. Thus, the larger the diameter of the semicircle, the higher the resistance, $R_{p}$ and, hence, the lower the corrosion rate [14]. One of the difficulties of the impedance technique clearly evidenced in the Nyquist diagram is the characterization of an essentially passive rebar. In this state, the charge transfer along the rebar, which denotes a corrosion process, is very small. Thus, the capacitive semicircles or arcs of charge transfer in the electric double layer are poorly developed, compromising data interpretation.

A corrosive process involves several simultaneous physical processes; hence, its equivalent circuit is composed of different circuit elements. However, the circuit elements may also vary from one case to another in the way they are interconnected. Christensen et al. [15, 16] proposed a correlation between the corrosion phenomenon and the equivalent circuit which is widely accepted in many researches. Figure 1(a) illustrates the equivalent circuit proposed by these authors. 


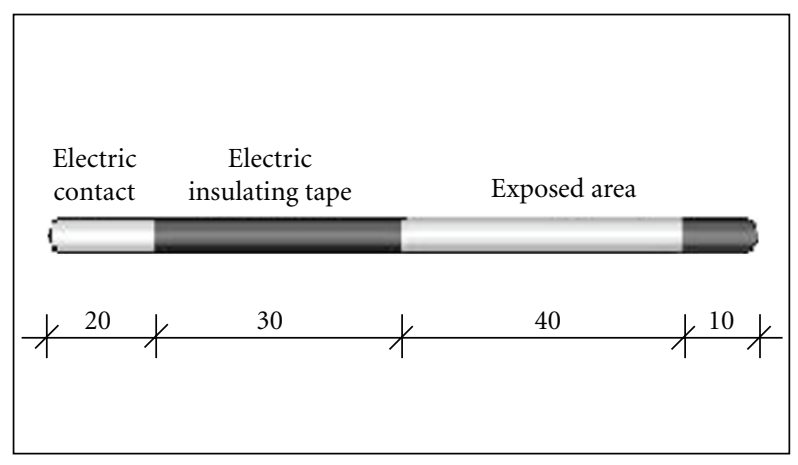

(a)

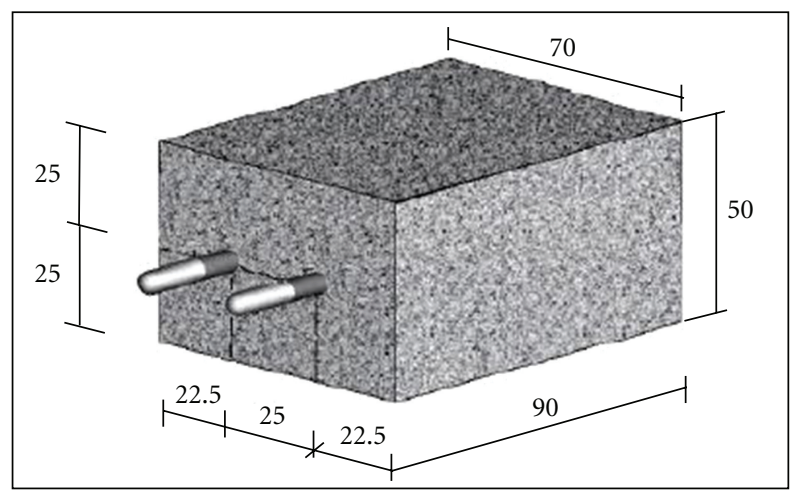

(c)

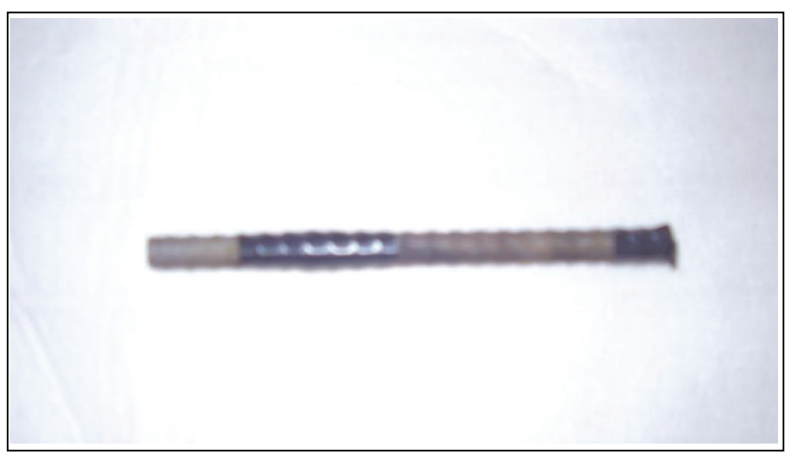

(b)

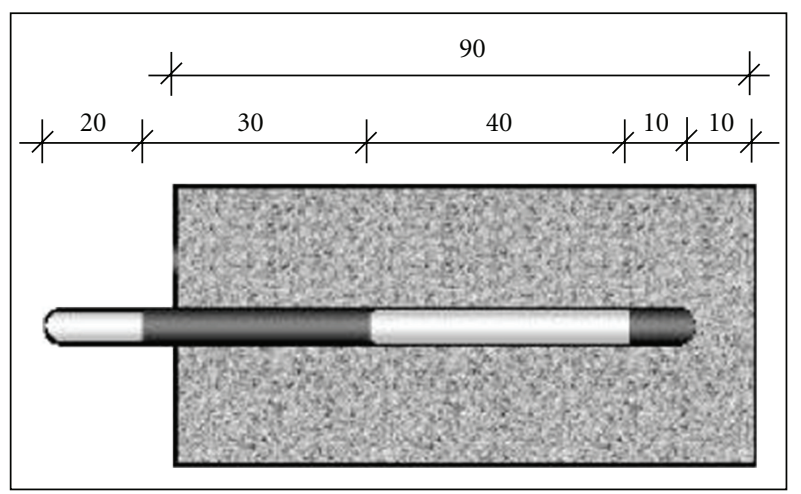

(d)

Figure 2: (a,b) Scheme of the exposed rebar area (in $\mathrm{mm}$ ), (c) sample dimensions (in $\mathrm{mm}$ ), and (d) steel rebar positions in concrete samples.

The equivalent diagram depicted in Figure 1(a) is associated with an apparent "offset resistance" $\left(R_{0}\right)$ connected in series to the concrete bulk $\left(R_{2} Q_{2}\right)$ and the electrode $\left(R_{e} Q_{e}\right)$. These elements are best viewed in the Nyquist diagram shown in Figure 1(b).

As can be seen, there are countless possible equivalent circuits that are suitable for different ways of evaluating the various materials used in the production of concrete. This makes the determination of an equivalent circuit that fully represents all the phenomena observed in the corrosion process a time-consuming task.

\section{Materials and Methods}

2.1. Materials. The concrete was produced with a Brazilian Portland cement (CPII Z-32, according to the Brazilian NBR 11578 standard), which is equivalent to the ASTM C 596 standard (Pozzolan-modified Portland cement). This cement contains pozzolan and is one of the most widely used cements in the state of São Paulo, Brazil. The coarse aggregate was dense, crushed granite stone and the fine aggregate was natural siliceous sand, available in São Carlos, SP, Brazil.

The red mud was supplied by ALCOA Brazil and came from Poços de Caldas, MG. It is a mixture containing about $60 \%$ of solids, collected immediately after the recovery of alumina from the digestion process (Bayer Process).

\subsection{Methods}

2.2.1. Characterization of Materials and Preparation of Concrete Samples. The materials were characterized by X-ray diffraction (Rigaku Geigerflex ME 210GF2 diffractometer) and X-ray fluorescence spectroscopy (Philips PW 1480 XRF spectrometer), while physical parameters such as specific surface area (estimated by BET, using a Micrometrics Gemini 2370 V1.02 analyzer) and specific gravity (Micrometrics Helium Pycnometer Accupyc 1330 V2.01) were also determined.

Concrete was prepared with ordinary Portland cement and red mud mixed in the following proportions: 1.0 (Portland cement): 1.5 (fine aggregate):1.3 (coarse aggregate) and a water/cement ratio of 0.5 . Red mud was added in partial substitution of Portland cement in the proportions of 10,20 , and 30 (wt $\%$ ). The mortar content was $75 \%$, and the cement consumption was $526 \mathrm{~kg} / \mathrm{m}^{3}$. Samples without red mud (reference) were also prepared.

Two commercial steel rebars (Gerdau, type CA-50) with a diameter of $6.3 \mathrm{~mm}$ were embedded in each prismatic concrete block $\left(50 \times 70 \times 90 \mathrm{~mm}^{3}\right)$ with a concrete topping of $2.25 \mathrm{~cm}$ (Figure 2). With this geometry, the distance between the inner surfaces of the steel rebars was $2.5 \mathrm{~cm}$ and the exposed embedded area of each electrode was $15.83 \mathrm{~cm}^{2}$.

Concrete blocks were demolded $24 \mathrm{~h}$ after being cast and were cured for 4 weeks in a saturated humidity chamber before immersion in the aggressive solutions.

2.2.2. Electrochemical Impedance Spectroscopy (EIS). The prismatic concrete specimens were subjected to monthly cycles of oven drying (one week) and partial immersion in a $3 \mathrm{wt} \% \mathrm{NaCl}$ solution in distilled water (3 weeks). Three 


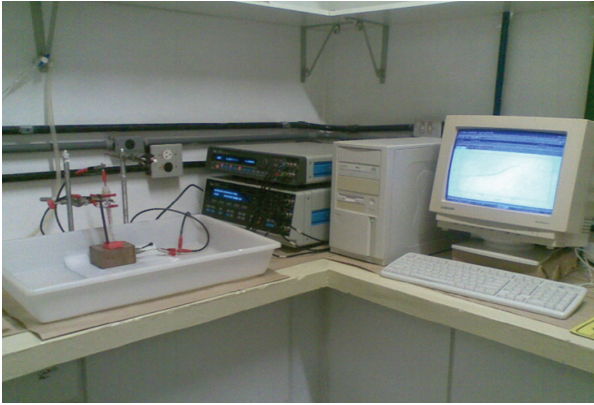

(a)

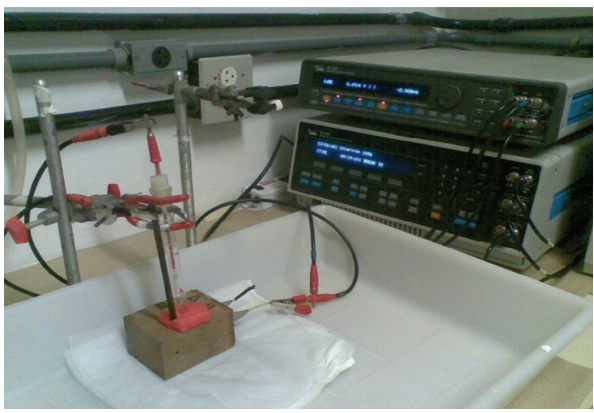

(b)

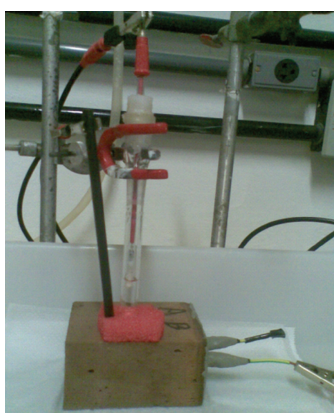

(c)

FIgURE 3: Apparatus for measuring the corrosion process by electrochemical impedance spectroscopy (EIS).

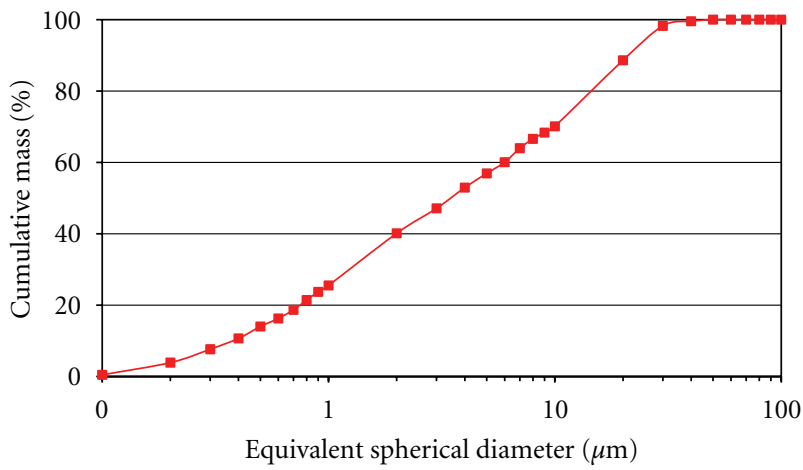

Figure 4: Particle size distribution of the dry red mud.

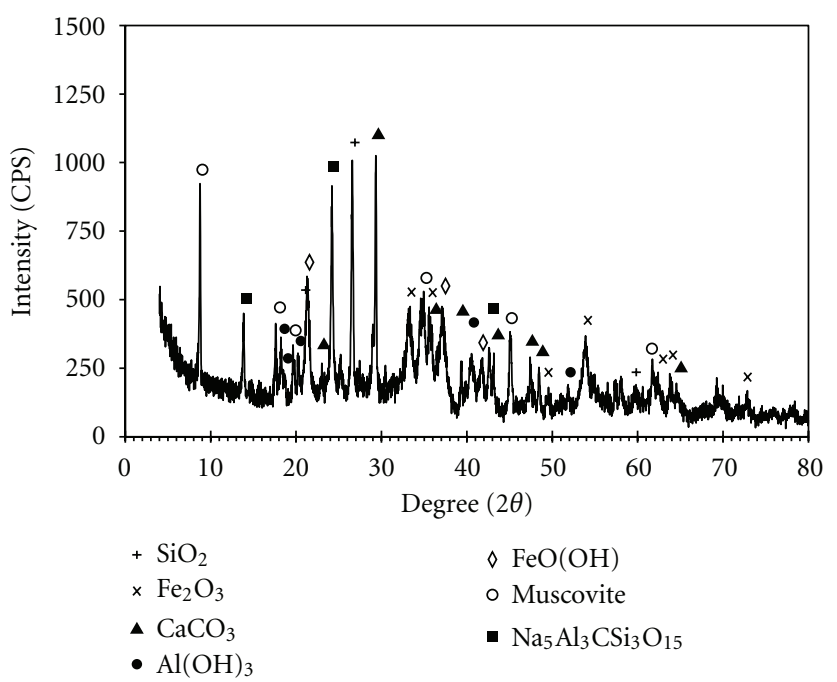

FIGURE 5: X-ray diffraction (XRD) pattern of dry red mud.

specimens of each composition were tested, and an average of six results (two rebars per sample) is presented.

Before starting each measurement, the cell was assembled using the saturated calomel electrode ( $\mathrm{SCE}, \mathrm{Hg} / \mathrm{Hg}_{2} \mathrm{SO}_{4}$ sat $\mathrm{K}_{2} \mathrm{SO}_{4}$ ) as reference and the counter electrode (carbon) was placed on the concrete surface, providing a wet sponge to assure a good electrolytic contact, with the rebars serving as the working electrodes.

The EIS measurements were taken with a Solartron 1287A potentiostat/galvanostat and a Solartron 1260 impedance analyzer, both monitored by computer with ZPlot/CorrWare V. 2.3 software. The parameters used in this impedance scan were

(i) initial frequency: $50 \mathrm{KHz}$,

(ii) final frequency: $10 \mathrm{mHz}$,

(iii) amplitude (rms): $5 \mathrm{mV}$,

(iv) ambient temperature: $(23 \pm 2)^{\circ} \mathrm{C}$,

(v) current range: $1 \mathrm{~A}$ a $100 \mathrm{nA}$,

(vi) electrochemical potential: Ecorr,

(vii) total time for each test: 30 minutes.

The results were analyzed using ZView 2 software. Measurements were taken at 30-day intervals for the first three months and at 60-day intervals thereafter. Thus, measurements were taken at $1,2,3,5,7,9,11$, and 13 months of age. A minimum of three samples ( 6 electrodes) were tested in all determinations.

Figure 3 illustrates the setup of the test apparatus to measure the corrosion process by EIS. 


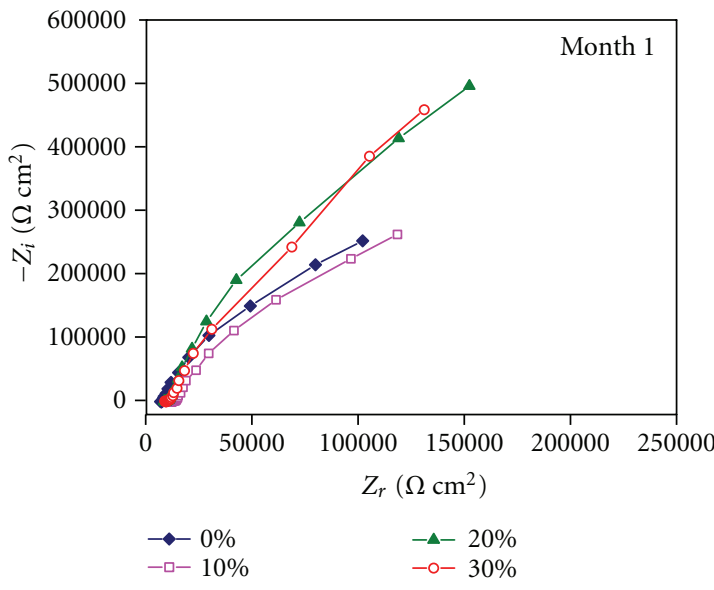

(a)

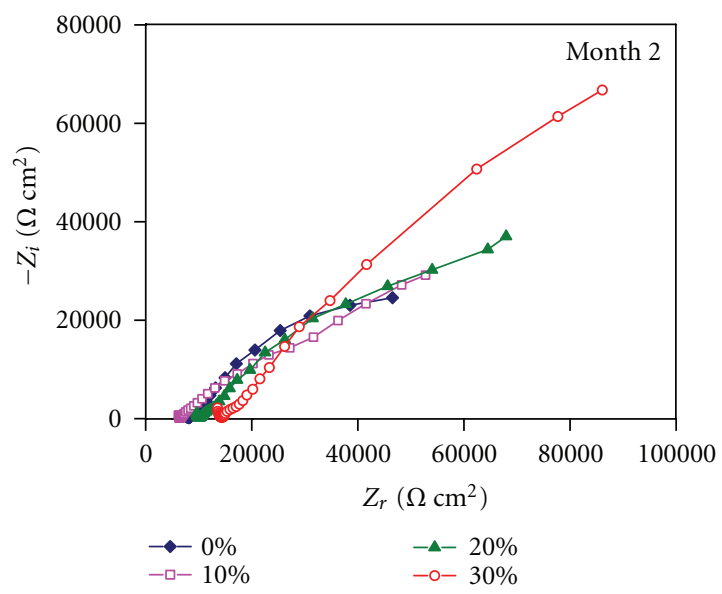

(b)

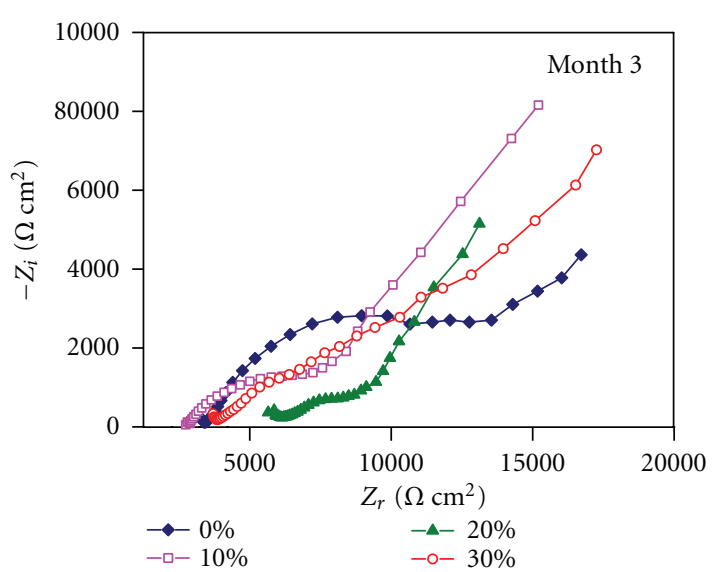

(c)

Figure 6: Continued.
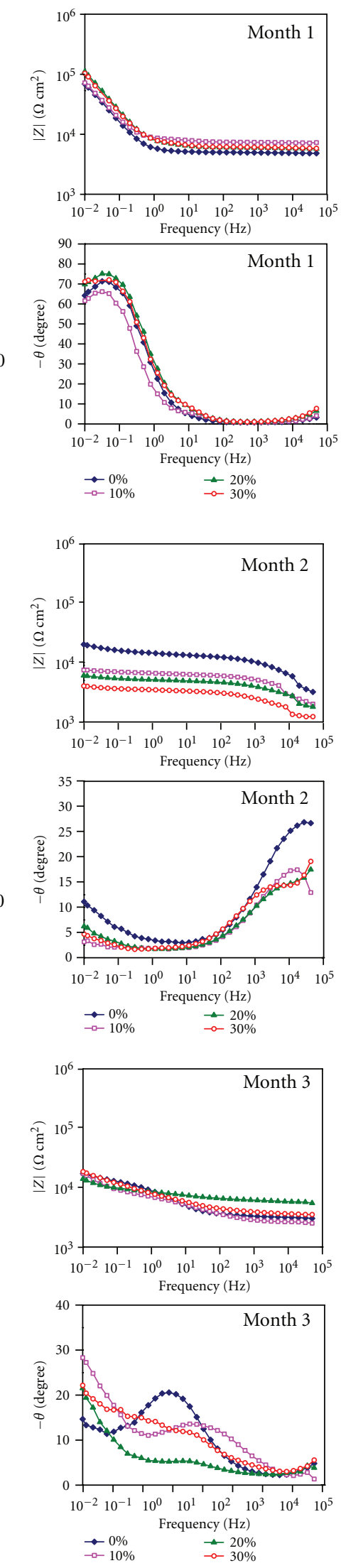

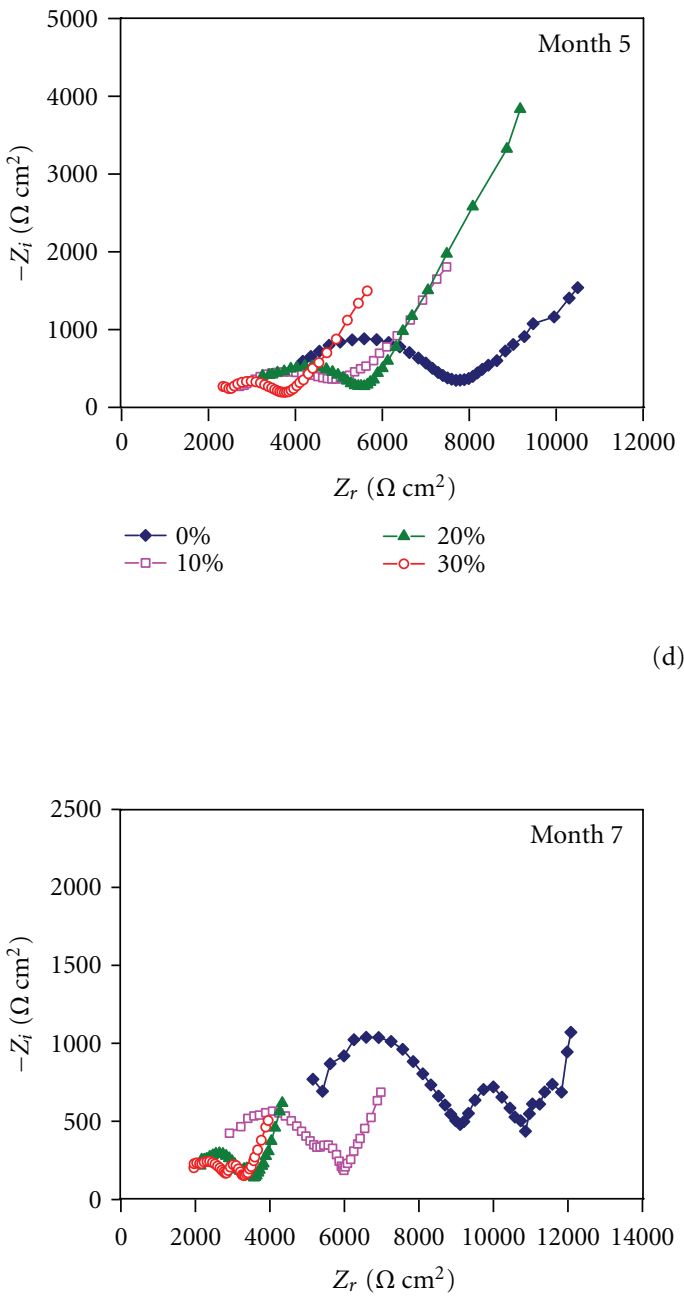

$$
\begin{array}{ll}
-\bullet 0 \% & -\Delta-20 \% \\
-\square-10 \% & -0-30 \%
\end{array}
$$

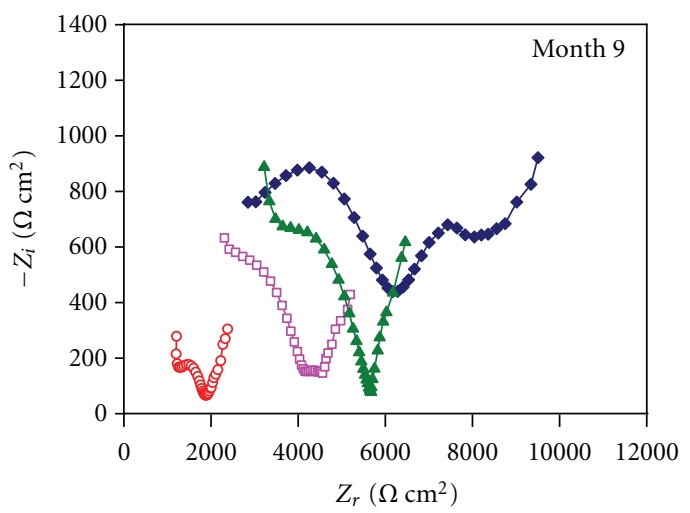

$$
\begin{array}{ll}
-\bullet 0 \% & -\Delta-20 \% \\
-\square-10 \% & -\circ-30 \%
\end{array}
$$
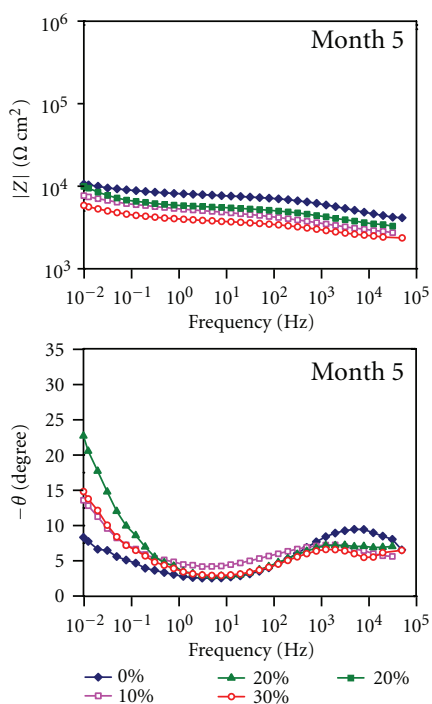

(d)
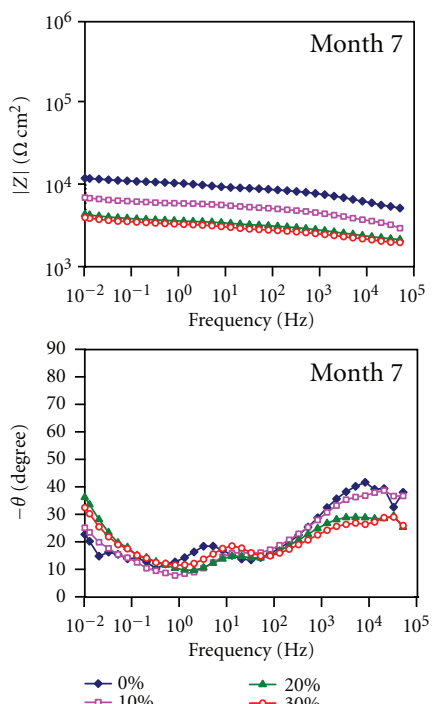

(e)
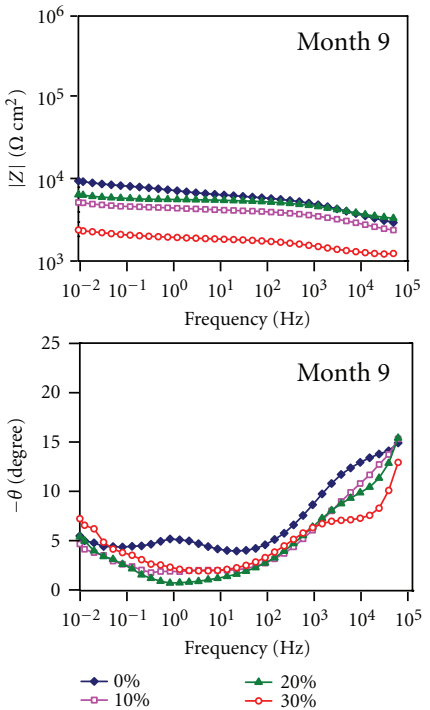

(f)

Figure 6: Continued. 

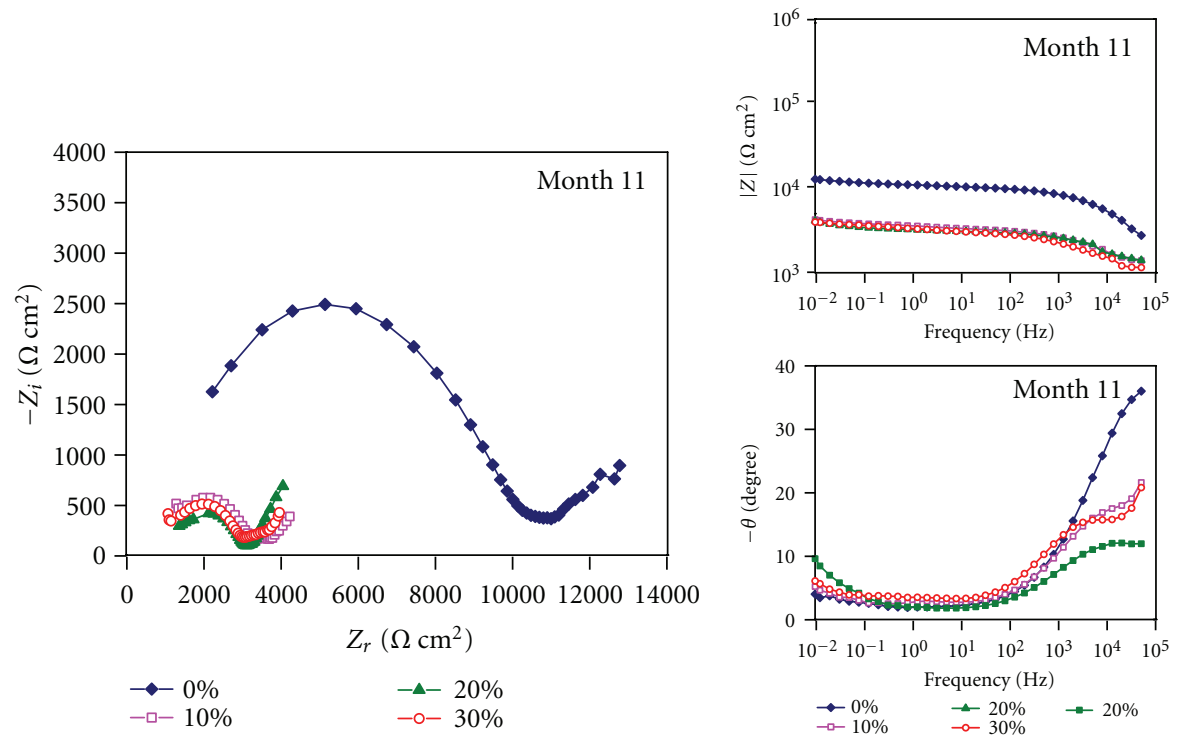

$(\mathrm{g})$
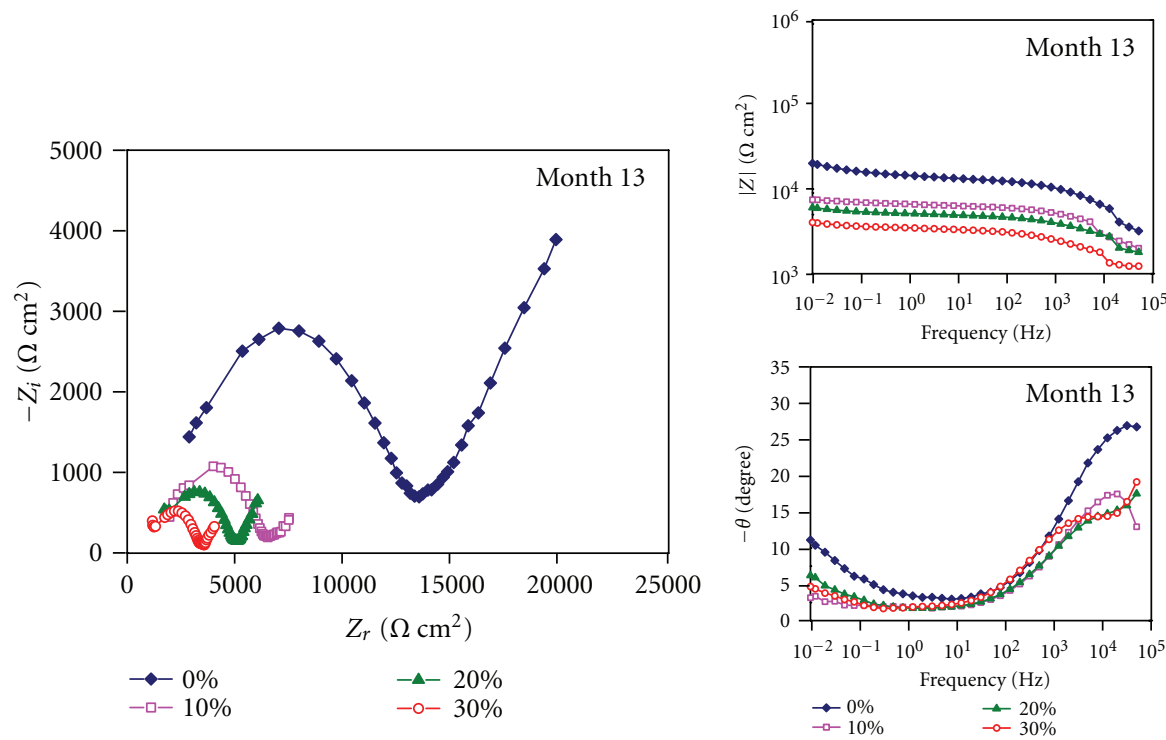

(h)

Figure 6: Impedance spectra (Nyquist and Bode diagrams) of concrete samples without red mud and with red mud contents of 10, 20, and 30 wt\%: (a) 1 month; (b) 2 months; (c) 3 months; (d) 5 months; (e) 7 months; (f) 9 months; (g) 11 months; (h) 13 months of age.

\section{Results and Discussion}

3.1. Materials Characterization. The Portland cement used here had a specific surface area of $0.93 \mathrm{~m}^{2} / \mathrm{g}$ and a specific gravity of $3.11 \mathrm{~kg} / \mathrm{dm}^{3}$. The sand had a specific surface area of $0.68 \mathrm{~m}^{2} / \mathrm{g}$ and a specific gravity of $2.70 \mathrm{~kg} / \mathrm{dm}^{3}$, classified by the Brazilian NBR 7211 standard as fine sand. The gravel had a specific gravity of $2.74 \mathrm{~kg} / \mathrm{dm}^{3}$ and a maximum dimension of $19 \mathrm{~mm}$.

The red mud was received in the form of paste containing about $40 \%$ free water. In the present study, the material was dried and crushed, and then used as a powdered additive. Ideally, to demonstrate its potential as a concrete constituent, red mud should be tested in the as-received condition; hence, the free water present in the mud should be considered a mortar mix component.

The red mud had a specific surface area of $20.27 \mathrm{~m}^{2} / \mathrm{g}$, as indicated by the particle fineness shown in Figure 4. Maximum particle size was under $40 \mu \mathrm{m}$, and the mean value was only about $8 \mu \mathrm{m}$. Its specific gravity was $2.90 \mathrm{~kg} / \mathrm{dm}^{3}$, and its $\mathrm{pH}$ was very high (12.95), exceeding the limit (12.5) established by the Brazilian NBR 10004 standard for nonhazardous wastes.

Table 1 presents the chemical composition of the waste, while Figure 5 shows the corresponding XRD pattern. As expected, the predominant crystalline components were aluminium hydroxide $\left(\mathrm{Al}(\mathrm{OH})_{3}\right)$, calcium carbonate $\left(\mathrm{CaCO}_{3}\right)$, and iron oxide $\left(\mathrm{Fe}_{2} \mathrm{O}_{3}\right)$, but relative amounts of $\mathrm{SiO}_{2}$, 
TABLE 1: Chemical composition of red mud estimated by XRF.

\begin{tabular}{lcccccccccc}
\hline Component & $\mathrm{Al}_{2} \mathrm{O}_{3}$ & $\mathrm{Fe}_{2} \mathrm{O}_{3}$ & $\mathrm{Na}_{2} \mathrm{O}$ & $\mathrm{CaO}$ & $\mathrm{SiO}_{2}$ & $\mathrm{~K}_{2} \mathrm{O}$ & $\mathrm{MnO}$ & $\mathrm{TiO}_{2}$ & $\mathrm{Others}^{2}$ & $\mathrm{LOI}^{\mathrm{a}}$ \\
\hline Content (wt.\%) & 19.87 & 19.85 & 7.35 & 4.61 & 14.34 & 1.87 & 0.21 & 2.66 & 1.01 & 27.20 \\
\hline
\end{tabular}

${ }^{\mathrm{a}} \mathrm{LOI}=$ loss of ignition.

muscovite, and $\mathrm{FeO}(\mathrm{OH})$ were also relevant. Some of those oxides were also detected by XRD, in addition to aluminium hydroxide and a complex $\mathrm{Na}_{5} \mathrm{Al}_{3} \mathrm{CSi}_{3} \mathrm{O}_{15}$ phase.

3.2. Electrochemical Impedance Spectroscopy (EIS). Initially, EIS measurements were taken every 30 days. However, after the first three months of analysis, this interval was increased to two months. Thus, measurements were taken at 1, 2, 3, 5, $7,9,11$, and 13 months of age. A minimum of 3 samples ( 6 electrodes) were tested in all determinations. For purposes of clarity, the graphs of only one of these measurements for each red mud content and at each age are presented (the results closest to the average and hence the most representative ones were chosen). The results are shown in Figure 6.

In the Nyquist diagrams obtained, note that most of the spectra show similar characteristics: two incomplete arcs in different frequency regions. A time constant $R C$ related to these arcs is represented by elements of an electrical circuit (resistor in parallel with a capacitor). In some cases, the formation of a third arc was observed, making the interpretation of the results more complex and raising doubts about the associated phenomena.

To obtain information from EIS measurements requires a physical model of the system that allows the equivalent circuit elements to be correlated with their properties and with the description of the phenomena. Based on the characteristics of the material (concrete) and the possibilities suggested in the literature, the equivalent circuit that best fits the results is proposed in Figure $7(\mathrm{a})$, where $R_{0}, R_{2}$, and $R_{e}$ represent, respectively, the "offset resistance" (high frequencies), the concrete bulk resistance (medium frequencies), and the electrode resistance (low frequency). Thus, $R_{e}$ represents the corrosion phenomenon in steel rebars. Note that the $\mathrm{R}_{0}$ value is usually neglected and $R_{b}\left(R_{b}=R_{0}+R_{2}\right)$ is considered the typical concrete bulk corrosion resistance.

The analysis of the data became increasingly complex starting from the measurements in the seventh month, when the degree of corrosion was already considerable, due to overlapping phenomena and to noise in the measurement resulting from the heterogeneity of the samples.

In view of these difficulties, we decided to change the way in which the analysis was performed. The basic theory states that these processes have a characteristic angular relaxation frequency, $w$ (starting from which they no longer respond), which is given by $w=1 / R C$ and which can also be read graphically at the top of the arc of the impedance spectrum $[17,18]$. Thus, we sought to associate the analyzable arcs with the typical capacitances and frequencies of each phenomenon.

The identified arcs were therefore isolated and related to each of the phenomena and a local analysis was performed,

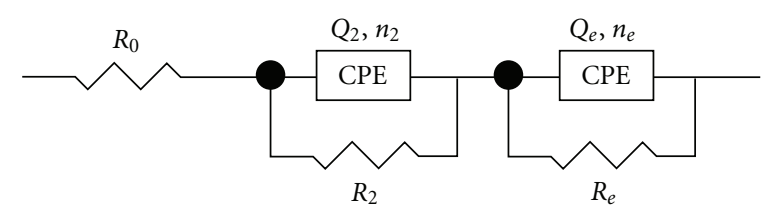

(a)

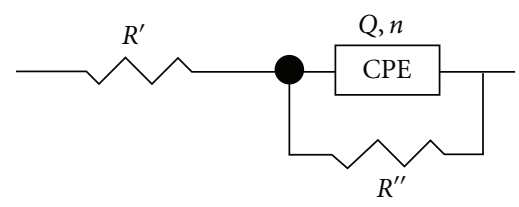

(b)

Figure 7: Equivalent electrical circuits proposed for the steelconcrete interface, based on (a) a general analysis and (b) analysis of individual arcs (simplified circuit).

which improved the accuracy. A similar strategy was adopted by Vermoyal et al. [17] in their studies. To this end, we used the simplified circuit shown in Figure 7(b).

When arcs are analyzed separately and fitted according to the simplified electrical circuit (Figure $7(b)$ ), one obtains the following results: the arc resistance $\left(R^{\prime \prime}\right)$, the values of the constant phase element (CPE), $Q$, and the " $n$ " index. This index measures the perfection of this element, varying between 0 and 1 , and comes closer to the unit value as the CPE approaches a perfect capacitor, $C[14,15,19]$. Thus, the characteristic capacitance, $C$, can be calculated according to

$$
C=Q^{1 / n} \cdot R^{(1-n) / n}
$$

The characteristic frequency $(f)$ associated with this characteristic capacitance is calculated in Hertz, according to (2), where $w=1 / R C[14,18]$ :

$$
\begin{gathered}
f(H z)=\frac{w}{2 \pi}, \\
f(H z)=\frac{1}{2 \pi \cdot R \cdot C} .
\end{gathered}
$$

This correlation between the characteristic capacitances and characteristic frequencies calculated for each phenomenon is shown in Figure 8. The typical frequencies found for the specimens used in this study can be grouped as follows:

(i) low frequencies in the range of $1 \mathrm{mHz}$ to $10 \mathrm{~Hz}$ $\left(10^{-3}-10 \mathrm{~Hz}\right)$ correspond to the electrode resistance $\left(R_{\mathrm{e}}\right)$ and are thus related to the corrosion phenomenon. The characteristic capacitance of this frequency band ranges from $10^{-6}$ to $10^{-3} \mathrm{~F} / \mathrm{cm}^{2}$;

(ii) medium frequencies in the range of $100 \mathrm{~Hz}$ to $\mathrm{MHz}$ $\left(10^{2}-10^{6} \mathrm{~Hz}\right)$ correspond to the concrete resistance 


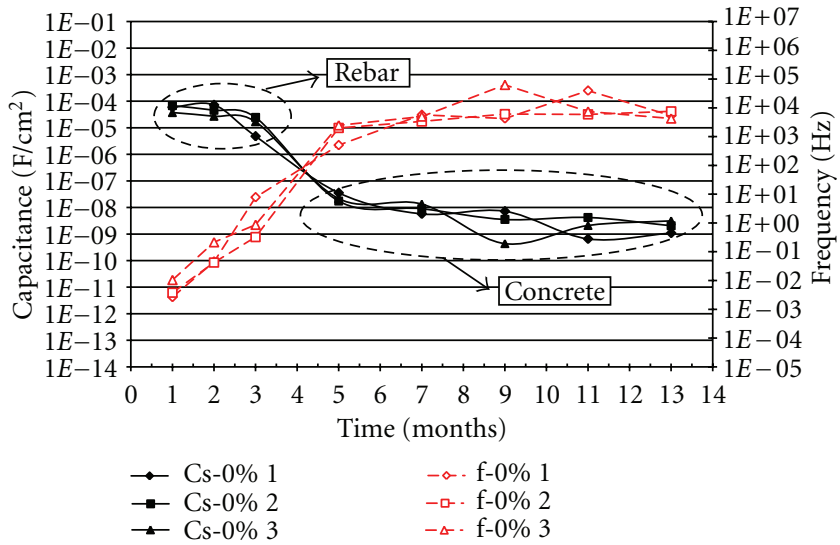

(a)

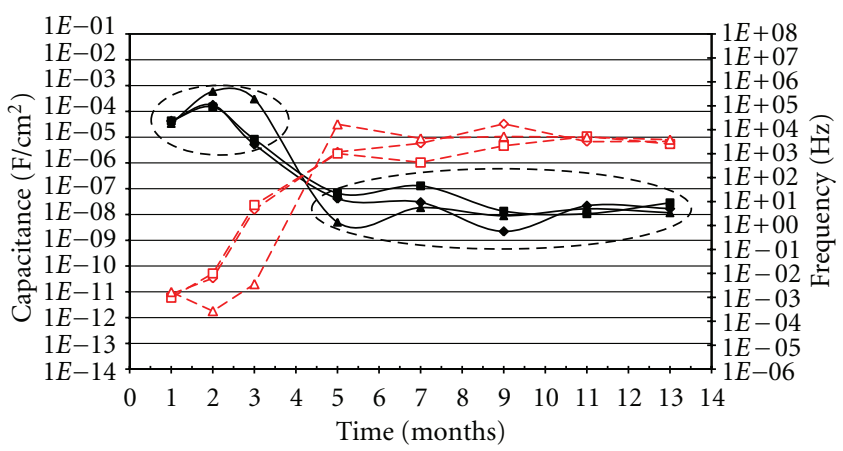

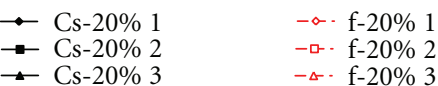

(c)
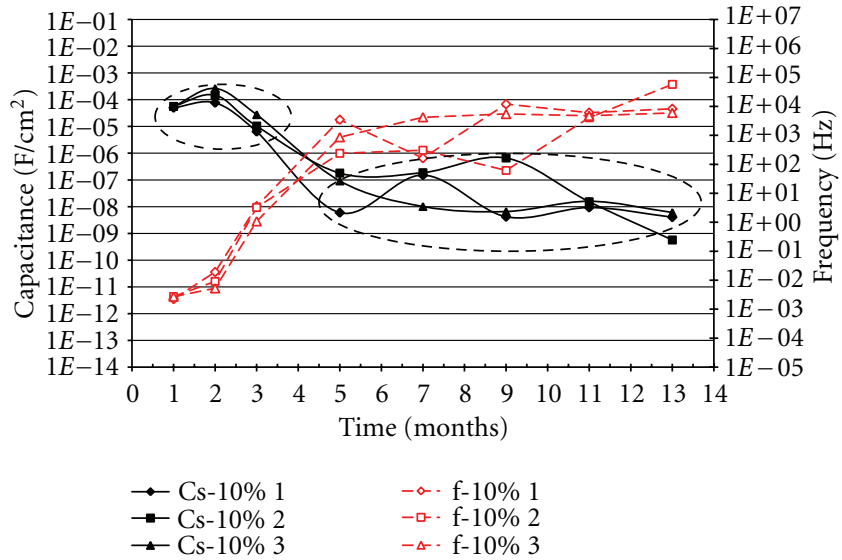

(b)

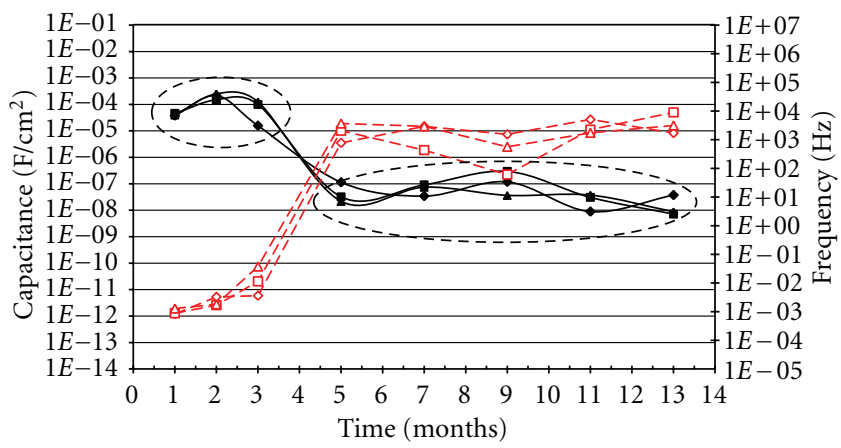

$\begin{array}{ll}\rightarrow \text { Cs-30\% } 1 & \text { - }-\mathrm{f}-30 \% 1 \\ \rightarrow \text { Cs-30\% } 2 & - \text { - }-\mathrm{f}-30 \% 2\end{array}$

- $\mathrm{Cs}-30 \% 3$

(d)

FIGURE 8: Examples of correlation between the characteristic capacitance and frequency of each of the phenomena observed by EIS for (a) reference concrete samples and for samples with varying red mud contents: (b) $10 \mathrm{wt} \%$; (c) $20 \mathrm{wt} \%$; (d) $30 \mathrm{wt} \%$.

$\left(R_{2}\right)$ and are related to the characteristics of the concrete surrounding and protecting the rebar. The characteristic capacitance of this frequency band lies between $10^{-9}$ and $10^{-6} \mathrm{~F} / \mathrm{cm}^{2}$;

(iii) high frequencies above the $\mathrm{MHz}$ range $\left(>10^{6} \mathrm{~Hz}\right)$ are associated with the "offset resistance" $\left(R_{0}\right)$, whose relevance is minor and whose values were neglected in this study.

Values similar to those shown in Figure 8 have been reported by other authors [14]. The results obtained for concrete corrosion resistance, $R_{b}$ (Ohms), for different red mud contents are given in Table 2 .

As can be seen in Table 2, the concrete corrosion resistance, $R_{b}$, increased over time. A similar behavior was observed in a recent study involving concrete resistance tests [20]. However, due to the aggressiveness of the drying and wetting cycles in $\mathrm{NaCl}$ solution, the concentration of chloride ions (highly conductive) inside the specimens increased considerably after a certain period of time. Allied to this fact, the presence of small cracks caused by the drying/wetting cycle and by expansion due to the fact that the onset of the corrosion process caused the concrete resistance to decline
TABLE 2: EIS results of the corrosion resistance, $R_{b}$ (Ohms), of reinforced concrete without red mud (reference) and with different red mud contents $(10,20$, and $30 \mathrm{wt} \%)$.

\begin{tabular}{lcccc}
\hline Age (months) & \multicolumn{5}{c}{ Corrosion resistance, $R_{b}(\Omega)$} \\
& $\begin{array}{c}\text { Reference } \\
(0 \%)\end{array}$ & $10 \%$ & $20 \%$ & $30 \%$ \\
\hline 1 & 9527.4 & 15453.0 & 13934.0 & 13763.0 \\
2 & 7494.8 & 8224.7 & 9671.6 & 21304.7 \\
3 & 15528.7 & 18036.7 & 25407.7 & 23312.8 \\
5 & 31113.7 & 27623.3 & 64915.7 & 39640.9 \\
7 & 6867.0 & 5536.7 & 3566.5 & 3387.6 \\
9 & 7615.7 & 5079.7 & 6112.0 & 5731.2 \\
11 & 7914.2 & 3239.3 & 3790.7 & 3586.3 \\
13 & 13188.5 & 5983.1 & 4773.3 & 4580.9 \\
\hline
\end{tabular}

again, reaching extremely low values at the end of the test. Silva [21] associated this fact to the samples' higher moisture content.

It was found that until this inversion in behavior occurred (in this study, after five months of analysis), 
TABLE 3: EIS results of the electrode resistance, $R_{e}\left(=R_{b}\right.$, Ohms), of reinforced concrete without red mud (reference) and with different red mud contents $(10,20$, and $30 \mathrm{wt} \%)$.

\begin{tabular}{lcccc}
\hline Age (months) & \multicolumn{5}{c}{ Electrode resistance, $R_{e}=R_{p}(\Omega)$} \\
& $\begin{array}{c}\text { Reference } \\
(0 \%)\end{array}$ & $10 \%$ & $20 \%$ & $30 \%$ \\
\hline 1 & $1.99 E+06$ & $1.23 E+06$ & $3.33 E+06$ & $6.42 E+06$ \\
2 & $1.79 E+05$ & $1.53 E+05$ & $2.79 E+05$ & $1.11 E+06$ \\
3 & $7.66 E+03$ & $1.20 E+04$ & $1.08 E+04$ & $1.20 E+05$ \\
5 & $5.44 E+03$ & $4.46 E+03$ & $3.16 E+03$ & $3.40 E+03$ \\
7 & $2.24 E+03$ & $1.55 E+03$ & $1.93 E+03$ & $1.20 E+03$ \\
9 & $3.14 E+03$ & $1.45 E+03$ & $1.50 E+03$ & $1.11 E+03$ \\
11 & $3.18 E+03$ & $1.44 E+03$ & $1.34 E+03$ & $9.69 E+02$ \\
13 & $3.09 E+03$ & $1.60 E+03$ & $2.68 E+03$ & $1.33 E+03$ \\
\hline
\end{tabular}

the samples with various red mud contents behaved similarly to the reference samples (without red mud), and even better at some points. However, the reference samples appeared to be more resistant to the aging of the experimental procedure, since their resistance declined less than the other samples.

Table 3 presents the results obtained for the electrode resistance, $R_{e}\left(=R_{p}\right.$, ohms), as a function of the various red mud contents.

According to some studies $[14,21]$, the rebar is in the process of corrosion if the diameter of semicircle formed at low frequencies is decreased, as observed in the Nyquist diagram. Therefore, the lower the $R_{e}$ values, the more advanced the corrosion process.

The results presented in Table 3 clearly show a reduction in $R_{e}$ values, reaching differences of one order of magnitude between successive measurements, which stabilize at around $10^{3} \Omega$ (or $\mathrm{K} \Omega$ ). Several aspects of these results should be highlighted, as follows. (i) The stabilization of these $R_{e}$ values coincided with the inversion in the behavior of the $\mathrm{R}_{b}$ values, suggesting that this was in fact the moment when the corrosion process was at its highest level. (ii) The reference specimens $(0 \%$ red mud content) reached this stabilization value earlier than the other samples (at three months of analysis), indicating that the corrosive process in the early stages was more pronounced in the reference samples than in the samples containing red mud. (iii) The typical electrode resistance in an advanced corrosion process is in the order of $\mathrm{K} \Omega$.

The analysis of the EIS results revealed the evolution of the corrosion kinetics, identifying the moment when the corrosive process reached an advanced stage. However, the difficulties involved in their interpretation and the uncertainties about the parameters and characteristic ranges of the phenomena indicate that this technique still requires more in-depth study.

\section{Conclusions}

This research led to the following conclusions:

(i) electrochemical impedance spectroscopy (EIS) is a highly reproducible and powerful technique. However, its application is limited by the difficulties involved in interpreting EIS data and by the lack of internationally accepted criteria, indicating that this technique still lacks in-depth studies;

(ii) the relationship between the arcs observed in the spectroscopy results and the characteristic relaxation frequency proved to be an interesting alternative for the analysis of heterogeneous and complex systems such as reinforced concrete, increasing the accuracy of measurements;

(iii) the phenomena involved in reinforcement corrosion and the inherent characteristics of concrete are observed at low $\left(10^{-3}-10 \mathrm{~Hz}\right)$ and medium $\left(10^{2}-\right.$ $\left.10^{6} \mathrm{~Hz}\right)$ frequencies, respectively. The typical electrode resistance of an advanced corrosion process is the order of $\mathrm{K} \Omega\left(10^{3} \Omega\right)$;

(iv) according to the Nyquist diagram, the rebar is undergoing corrosion when the semicircle formed at low frequencies is reduced;

(v) the EIS results indicated that the corrosion process was more advanced in the reference samples than in the samples containing red mud, indicating that this waste is a promising inhibitor of reinforced concrete corrosion.

\section{Acknowledgments}

The authors wish to thank CNPq-the National Council of Technological and Scientific Development (Brazil), PPGCEM/UFSCar-Postgraduate Program in Materials Science and Engineering at the Federal University of São Carlos (Brazil), and the UA/DECV-Department of Ceramics and Glass Engineering, CICECO, University of Aveiro (Portugal)—Project FCT-PTDC/CTM/65243/2006. This project was not funded by Alcoa Brazil.

\section{References}

[1] IBRAM-Brazilian Mining Association, “Bauxita," 2009, http://www.ibram.org.br/sites/1300/1382/00000033.pdf.

[2] Roskill Reports, “The economics of bauxite \& alumina," 2010, http://www.roskill.com/reports/industrial-minerals/bauxite/ leaflet.

[3] S. S. Amritphale, A. Anshul, N. Chandra, and N. Ramakrishnan, "A novel process for making radiopaque materials using bauxite-Red mud," Journal of the European Ceramic Society, vol. 27, no. 4, pp. 1945-1951, 2007.

[4] E. Kalkan, "Utilization of red mud as a stabilization material for the preparation of clay liners," Engineering Geology, vol. 87, no. 3-4, pp. 220-229, 2006.

[5] P. Asokan, M. Saxena, and S. R. Asolekar, "Coal combustion residues-environmental implications and recycling potentials," Resources, Conservation and Recycling, vol. 43, no. 3, pp. 239-262, 2005.

[6] S. S. Amritphale and M. Patel, "Utilisation of red mud, fly ash for manufacturing bricks with pyrophyllite," Silicates Industriels, vol. 2, pp. 31-35, 1987.

[7] V. M. Sglavo, S. Maurina, A. Conci, A. Salviati, G. Carturan, and G. Cocco, "Bauxite 'red mud' in the ceramic industry. Part 
2: production of clay-based ceramics," Journal of the European Ceramic Society, vol. 20, no. 3, pp. 245-252, 2000.

[8] N. Yalçin and V. Sevinç, "Utilization of bauxite waste in ceramic glazes," Ceramics International, vol. 26, no. 5, pp. 485493, 2000.

[9] P. E. Tsakiridis, S. Agatzini-Leonardou, and P. Oustadakis, "Red mud addition in the raw meal for the production of Portland cement clinker," Journal of Hazardous Materials, vol. 116, no. 1-2, pp. 103-110, 2004.

[10] M. Singh, S. N. Upadhayay, and P. M. Prasad, "Preparation of iron rich cements using red mud," Cement and Concrete Research, vol. 27, no. 7, pp. 1037-1046, 1997.

[11] M. F. Montemor, A. M. P. Simões, and M. G. S. Ferreira, "Chloride-induced corrosion on reinforcing steel: from the fundamentals to the monitoring techniques," Cement and Concrete Composites, vol. 25, no. 4-5, pp. 491-502, 2003.

[12] K. R. R. Freire, Avaliação do desempenho de inibidores de corrosão em armaduras de concreto, Ph.D. thesis, Federal University of Paraná (UFPR), Paraná, Brazil, 2005.

[13] S. Wolynec, Técnicas Eletroquímicas em Corrosão, EDUSP, São Paulo, Brazil, 1st edition, 2003.

[14] M. A. G. T. C. Machado, Inibidores de corrosão em concreto armado contra o ataque de agentes da chuva ácida, Ph.D. thesis, Federal University of São Carlos (UFSCar), São Carlos, Brazil, 2004.

[15] B. J. Christensen, R. T. Coverdale, R. A. Olson et al., "Impedance spectroscopy of hydrating cement-based materials: measurement, interpretation, and application," Journal of the American Ceramic Society, vol. 77, no. 11, pp. 2789-2804, 1994.

[16] B. J. Christensen, T. O. Mason, and H. M. Jennings, "Influence of silica fume on the early hydration of Portland cements using impedance spectroscopy," Journal of the American Ceramic Society, vol. 75, pp. 939-945, 1992.

[17] J. J. Vermoyal, A. Frichet, L. Dessemond, and A. Hammou, "AC impedance study of corrosion films formed on zirconium based alloys," Electrochimica Acta, vol. 45, no. 7, pp. 1039 1048, 1999.

[18] L. F. Maia and A. C. M. Rodrigues, "Electrical conductivity and relaxation frequency of lithium borosilicate glasses," Solid State Ionics, vol. 168, no. 1-2, pp. 87-92, 2004.

[19] R. T. Coverdale, R. A. Olson, B. J. Christensen et al., "Interpretation of the impedance spectroscopy of cement paste via computer modelling — part III: microstructural analysis of frozen cement paste," Journal of Materials Science, vol. 30, no. 20, pp. 5078-5086, 1995.

[20] D. V. Ribeiro, Influência da adição da lama vermelha nas propriedades e na corrosibilidade do concreto armado, Ph.D. thesis, Federal University of São Carlos (UFSCar), São Carlos, Brazil, 2010.

[21] F. G. Silva, Estudo de concretos de alto desempenho frente à ação de cloretos, Ph.D. thesis, University of São Paulo (USP), São Carlos, Brazil, 2006. 

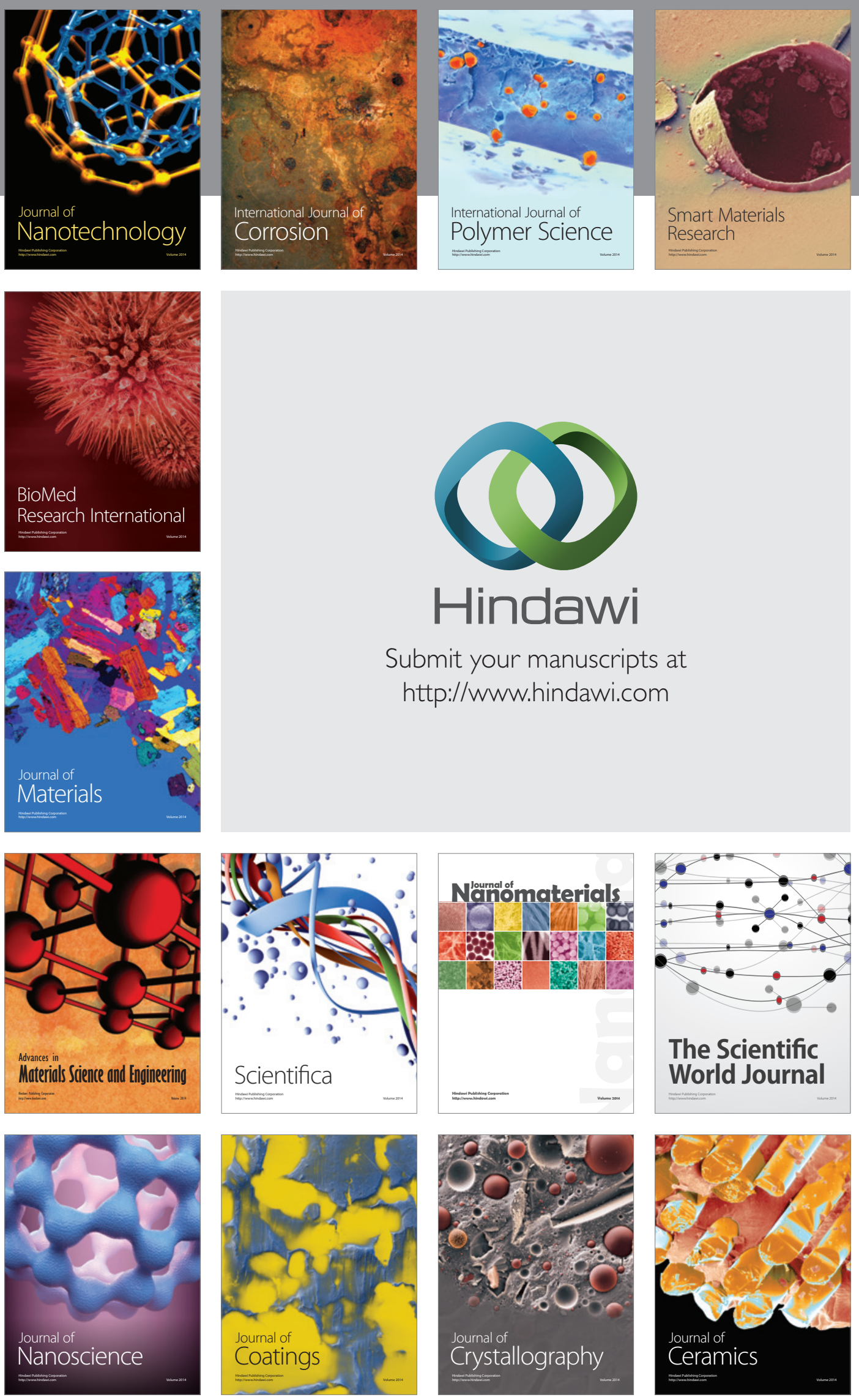

The Scientific World Journal

Submit your manuscripts at

http://www.hindawi.com

\section{World Journal}

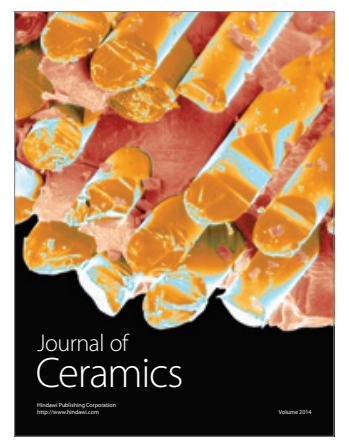

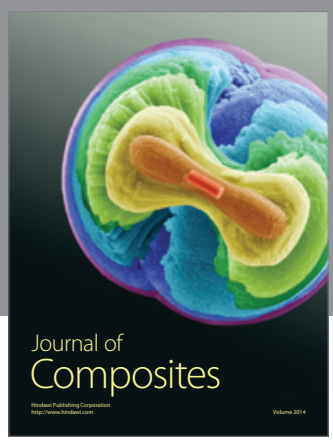
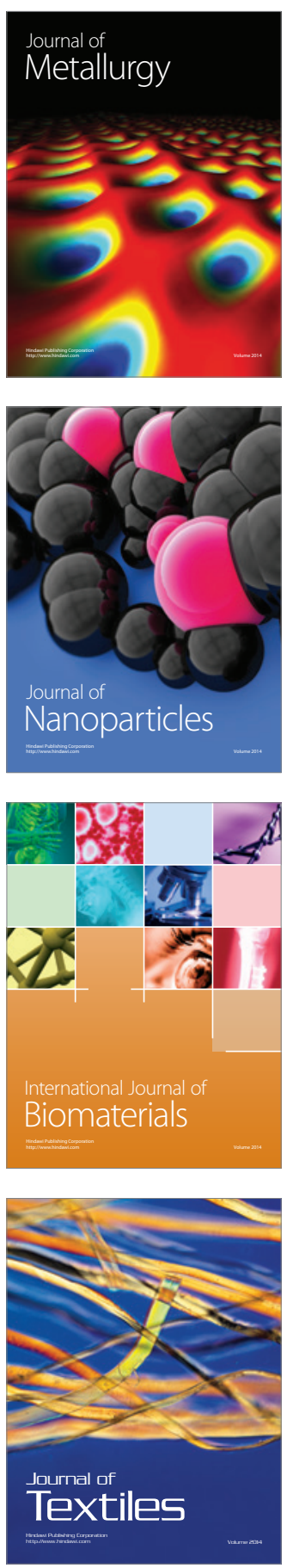